\title{
THE COMOVEMENTS IN INTERNATIONAL STOCK MARKETS: NeW EVIDENCE FROM LATIN AMERICAN EMERgING COUNTRIES
}

\author{
Mohamed El Hedi Arouri ${ }^{\mathrm{a}^{*}}$, Mondher Bellalah ${ }^{\mathrm{b}}$ and Duc Khuong Nguyen ${ }^{\mathrm{c}}$ \\ ${ }^{\mathrm{a}}$ LEO, Université d'Orléans mohamed.arouri@univ-orleans.fr; ${ }^{\mathrm{b}}$ Université de Cergy-Pontoise, \\ mondher.bellalah@u-cergy.fr; ${ }^{\mathrm{c}}$ ISC Paris School of Management, dnguyen@groupeisc.com; \\ Corresponding author.
}

\begin{abstract}
We analyze the time-variations of conditional correlations between selected Latin American emerging markets and between them and the World stock market to further shed light on the issues of capital market integration and portfolio diversification. The cross-market correlations are empirically estimated from the Engle (2002)'s DCC-GARCH model. Bai and Perron (2003)'s structural break analysis technique is also employed to test for possibly changing nature of stock market comovements. Main findings of the paper are as follows. First, the degree of cross-market comovements changed over time and has significantly increased since 1994 and onwards, which is to the large extent informative of increasing market integration. Despite the significant interdependencies among the studied markets, room for international portfolio diversification nevertheless seems largely possible. Second, it is demonstrated that the cross-market comovements are subjected to various regime shifts due essentially to major stock market events. Finally, the purpose that stock markets move much more together in times of crisis than in normal times can not be rejected according to our empirical evidence.
\end{abstract}

JEL Classification: F37; G15

Keywords: Stock market comovements, Latin American emerging markets, Multivariate GARCH models, Structural breaks. 


\section{INTRODUCTION}

Studies on the time-variation and nature of international stock market comovements have recently gained ground in international finance literature. This increase of interests and motivations can be explained by various reasons, but the most relevant of all include the international portfolio diversification issues and the recurrence of financial crises that occurred in both developed and emerging countries during the 1990's decade.

As far as the portfolio diversification is concerned, we already acknowledge that, according to the basic lessons drawn from both the mean-variance framework of Markowitz (1958) and the Capital Asset Pricing Model (CAPM) developed by Sharpe (1964) and Lintner (1965), investors, either individual or institutional, can reduce the volatility of their portfolios through allocating their investments in various classes of financial instruments, industries and other categories of assets that would move in different ways in response to the same event. In other words, diversification benefits can be achieved because a portfolio's performance depends not only on the return and risk characteristics of the assets being held in the portfolio, but also on the correlation (or comovement) of these assets. The lower is the correlation between assets; the higher are the diversification gains. Based on the same rules, diversifying internationally the portfolios is beneficial to investors only if stock markets in different countries do not move together. Thus, the portfolio diversification issue naturally raises the question of investigating the relationship between international stock markets. The ongoing process of globalization, thanks to the market openings decisions in many emerging market countries in the late 1980s and the resulting cross-border capital flows, also contributes to further expand the literature on stock market comovements. Indeed, since emerging markets are now accessible to foreign investors and they become more integrated into the world stock market (e.g., Bekaert and Harvey, 1995; Gerard and al., 2003; Carrieri and al., 2005), it is intriguing to question whether diversification benefits documented by Grubel (1968), Levy and Sarnat (1970), Lessard (1973), and Errunza (1977) have been significantly reduced.

The recurrence of financial crises during the 1990's decade, as we mentioned above, is another reason simulating the appetite of researchers for studying the comovement of inter- 
national stock markets. The rationale behind this appetite lies on the fact that financial institutions and policymakers would like to measure the intensity of the interdependences between national stock markets and thus to have a reliable management of contagion risk which results from potentially harmful spillovers of volatility across markets in time of distresses or crisis.

For instance, a number of theoretical and empirical studies have employed a wide variety of methods and data frequencies at both firm and country levels to model the comovement of international stock markets and searched for the reasons behind this phenomenon. The focus was mostly on the correlations and the stock return and volatility spillovers between stock markets around the world. Since the literature is so abundant to be reviewed exhaustively here, we only provide a brief review of the most relevant works in the following paragraphs.

In an earlier paper that opens the debate on the potential benefits of international diversification, Grubel (1968) develops a model of internationally diversified portfolios where investors hold both domestic assets and assets denominated in foreign currency from eleven industrial countries. According to the author's findings, international diversification of portfolio constitutes a possible source of welfare gains for individual investors and this increased performance comes from the low correlations between selected countries. Levy and Sarnat (1970), Lessard (1973) and Errunza (1977) also examine the international diversification potential, but the analysis is more general due to the simultaneous treatment of developed and developing countries. Their empirical results show the superiority of portfolios which are not limited to only securities issued by developed countries.

In the spirit of the aforementioned papers, the literature focusing on the comovement of international stock markets has grown rapidly and includes, among others, Eun and Shim (1989), Hamao and al. (1990), Karolyi (1995), Richards (1995), Harvey (1995), Forbes and Rigobon (2002), Johnson and Soenen (2003), Hsin (2004), Bekaert and al. (2005), Morana and Beltratti (2006), Gilmore and al. (2006), and Syriopoulos (2007). We generally observe that in recent works, the concept of comovement covers not only the correlations, but also the spillovers of stock returns (or prices) and volatility across equity markets. As a result, 
empirical strategies such as Granger (1969)'s causality test, Sims (1980)'s vector autoregressive models, Engle and Granger (1987)'s cointegration test and ARCH/GARCH methodology are largely employed. For example, Hamao and al. (1990) explore the relationships between three marketplaces New York, London and Tokyo from an ARCH-type model and find significant spillovers of prices and price volatility. In Gilmore and al. (2007), dynamic cointegration and principal components methods are applied to investigate the short-term and long-term comovements between European developed markets and those of three Central European countries. Overall, main results from the majority of these studies can be summarized as follows: $i$ ) significant comovements are observed among world stock markets; $i$ ) there is evidence of a positive relation between correlation and volatility, that is, correlations between international stock markets tend to be important in periods of high volatility or in the times of financial troubles.

Some papers have empirically examined the time-varying feature of international stock market comovements and searched for their determinants (e.g., Longin and Solnik, 1995; Erb and al., 1994; Karolyi and Stulz; 1996; Bae and al., 2003). For instance, using a GARCH model specification, Longin and Solnik (1995) document an increasing trend in the correlations among international equity markets and note that the correlation between these returns was dynamically changing in their research. Karolyi and Stulz (1996) studied the United States and Japan indices. They discovered evidence of changing correlations in the daily returns of these countries.

The issue of equity market comovement in Latin America has been investigated by several studies. For instance, Choudry (1997) employs unit root tests, cointegration tests and error correction models to examine the long-run relationship between six Latin American markets and the US market, and finds evidence of cointegration relationship and significant causality among these markets. In the same vein, Chen and al. (2002) investigate the interdependencies of six equity markets in Latin America (Argentina, Brazil, Chile, Colombia, Mexico and Venezuela) and document that diversification benefits are limited when investing in these markets particularly due to their high comovement. Christofi and Pericli (1999) show evidence of significant cross-market linkages in five Latin American markets (Argen- 
tina, Brazil, Chile, Columbia and Mexico) from combining a vector autoregressive (VAR) model with a multivariate exponential GARCH process. Johnson and Soenen (2003) examine the cross-country comovement for eight American equity markets with the US market using the Geweke (1982)'s measure of contemporaneous feedback between return series. Their sample includes equity markets from Argentina, Brazil, Chile, Mexico, Colombia, Peru, Venezuela, and Canada. They find a statistically significant linkage between eight equity markets of the Americas and the US stock market. Finally, in a recent paper, Fujii (2005) studies the intra and inter-causal linkages among eight emerging stock markets in Asia and Latin America. Four Latin American markets included in the sample are Argentina, Brazil, Chile and Mexico. Using standardized residuals estimated from an autoregressive process and a $\operatorname{GARCH}(1,1)$ model to calculate the residual correlation functions for the first and second moments of the stock returns, the author finds the existence of significant causal linkages both within each region and across the two regions. In addition, the causal linkages are found to be stronger during the time of major financial crises.

Our paper joins the above literature by focusing on the aggregate stock market comovements. We empirically investigate the comovement issue in the context of Latin American emerging markets since they rank among the most mature markets within the universe of emerging countries and they actually attract a particular attention from global investors thanks to their great market openness. We contribute to the related literature in several aspects. First, instead of modeling the comovement by VAR and realized correlations as in past studies which capture the causal linkages but do not permit to quantify the comovement, this paper directly infer the cross-market linkage from the stock data using a multivariate Dynamic Conditional Correlation GARCH model (DCC-GARCH). Second, we are interested in dating the structural breaks in the time-paths of the conditional correlation indices to highlight whether the cross-market comovement encompasses significant changes in nature or not. Finally, our methodology enables the investigation of the differences in stock market comovements between normal and crisis periods.

Overall, our findings indicate a clear upward trend in correlation from 1994 and onwards as a result of market liberalization and increased globalization. Interestingly, there are sud- 
den increases in conditional correlation following the Asian and Brazilian financial crises in 1997-1998 and, to less extent, the stock market crash in 1987 and the Latin American markets crises in 1994 and 2001. The results from the stability test typically reveal that structural breaks are present in the time-path of the cross-market conditional correlation series and often coincide with major stock market events such as financial market liberalizations, ADR introduction and crisis. Finally, our findings support those of previous works because they evidence that the inter-market comovements were significantly higher during the crisis period than during the tranquil period.

The remainder of the article is organized as follows. Section 2 describes the data employed in the paper. Section 3 presents our empirical methodology. Section 4 reports and interprets the empirical results. We provide some concluding remarks in Section 5.

\section{DATA}

Given the aim of the article, the data used are on monthly basis and consist of the S\&P's IFCG total return indices for the six main Latin American emerging markets and the MSCI World stock market index, sampled over the period January 1985 to August 2005. The Latin American emerging markets studied are: Argentina, Brazil, Chile, Colombia, Mexico, and Venezuela. All the indices are obtained from DataStream International and expressed in American dollars. They are converted to return using the log price relative filter. Descriptive statistics and stochastic properties of monthly returns are presented in Table 1.

\section{[Please insert Table 1 about here]}

Panel A reveals a number of interesting facts. Compared to World market, Latin American emerging markets have higher returns and risk. Chile has the highest monthly return followed by Colombia and Mexico. Argentina has the highest standard-deviation followed by Brazil and Venezuela.

The Engle (1982)'s test for conditional heteroscedasticity rejects the null hypothesis of no ARCH effects for Argentina, Brazil, Colombia and Mexico. Skewness is mostly negative and kurtosis is above three. The Jarque-Bera test statistic (JB) strongly rejects the hy- 
pothesis of normally distributed returns. These facts support our decision to use the quasimaximum likelihood (QML) approach of Bollerslev and Wooldridge (1992) to estimate and test the model.

The null hypothesis of no autocorrelation of order 12 is rejected for Chile, Colombia and Mexico. The first autocorrelation (reported in Panel B) is highly significant for these countries, which suggests that we need to include an auto-regressive correction in the mean equations.

Panel $\mathrm{C}$ reports the unconditional correlations among markets. As expected, there is a positive correlation between stock markets. The highest unconditional correlation is between Chile and Mexico (43.34\%) and the lowest one is between Argentina and Colombia $(7.00 \%)$. The values of the unconditional correlations are clearly low. This suggests that there are still benefits from diversification across Latin American emerging markets.

\section{METHODOLOGY}

\subsection{Modeling dynamic conditional correlation}

Finance literature on modeling the volatility of emerging stock market volatility has been extensively developed thanks to ARCH/GARCH-type models, which are respectively introduced by Engle (1982) and Bollerslev (1986). The examples of application include, among others, Bekaert and Harvey (1997,2000), Kim and Singal (2000), Miles (2002) and Jayasuriya (2005). As pointed out by past studies, GARCH models appear to successfully describe the stochastic properties of stock returns and correlation (i.e., time-variation and persistence).

In this paper we rely on the time-varying correlation coefficients estimated from a multivariate DCC-GARCH model developed by Engle (2002) to measure the comovements between Latin American emerging markets, and between them and the world stock market. This model is obviously suitable to our problem because it allows us to directly infer the cross-market conditional correlations and to avoid the proliferation of parameters to be estimated in full parameterization of BEKK GARCH. 
Assume that stock market returns from the $k$ series are multivariate normally distributed with zero mean and conditional variance-covariance matrix $H_{t}$, our multivariate DCCGARCH model can be presented as follows:

$$
\left\{\begin{array}{l}
r_{t}=\mu_{t}+\varepsilon_{t}, \varepsilon_{t} \mid I_{t-1} \rightarrow N\left(0, H_{t}\right) \\
H_{t} \equiv D_{t} R_{t} D_{t}
\end{array}\right.
$$

In these formulas, $r_{t}$ is the $(k \times 1)$ vector of the returns on stock market indices; $\varepsilon_{t}$ is a $(k \times 1)$ vector of zero mean return innovations conditional on the information available at time $t-1$; $\mu_{i, t}=\delta_{i 0}+\delta_{i 1} r_{i, t-1}+\delta_{i 2} r_{w, t-1}$ for emerging market $i$ and $\mu_{w, t}=\delta_{w o}+\delta_{w 1} r_{w, t-1}$ for the world market with $r_{w}$ denoting the return on world market index; $D_{t}$ is a $(k \times k)$ diagonal matrix with elements on its main diagonal being the conditional standard deviations of the returns on each market in the sample and $R_{t}$ is the $(k \times k)$ conditional correlation matrix and. $D_{t}$ and $R_{t}$ are defined as follows:

$$
D_{t}=\operatorname{diag}\left(h_{11 t}^{1 / 2} \ldots h_{k k t}^{1 / 2}\right)
$$

where $h_{i i t}$ is chosen to be a univariate $\operatorname{GARCH}(1,1)$ process;

$$
R_{t}=\left(\operatorname{diag} Q_{t}\right)^{-1 / 2} Q_{t}\left(\operatorname{diag} Q_{t}\right)^{-1 / 2}
$$

where $Q_{t}=(1-\alpha-\beta) \bar{Q}+\alpha u_{t-1} u_{t-1}^{\prime}+\beta Q_{t-1}$ refers to a $(k \times k)$ symmetric positive definite matrix with $u_{i t}=\varepsilon_{i t} / \sqrt{h_{i i t}}, \bar{Q}$ is the $(k \times k)$ unconditional variance matrix of $u_{t}$, and $\alpha$ and $\beta$ are non-negative scalar parameters satisfying $\alpha+\beta \prec 1$.

The conditional correlation coefficient $\rho_{i j}$ between two markets $i$ and $j$ is then expressed by the following equation:

$$
\rho_{i j}=\frac{(1-\alpha-\beta) \bar{q}_{i j}+\alpha u_{i, t-1} u_{j, t-1}+\beta q_{i j, t-1}}{\left((1-\alpha-\beta) \bar{q}_{i i}+\alpha u_{i, t-1}^{2}+\beta q_{i i, t-1}\right)^{1 / 2}\left((1-\alpha-\beta) \bar{q}_{j j}+\alpha u_{j, t-1}^{2}+\beta q_{j j, t-1}\right)^{1 / 2}}
$$

In this formulation, $q_{i j}$ refers to the element located in the $i$ th row and $j$ th column of the symmetric positive definite matrix $Q_{t}$. Accordingly, the estimation of the DCC-GARCH 
model as described above is can be estimated using a two-stage procedure. In the first stage, univariate $\operatorname{GARCH}(1,1)$ model is estimated for each time series. During the second stage, the transformed residuals from the first stage (i.e., the estimated residuals are standardized by their conditional standard deviations) are used to infer the conditional correlation estimators. The log-likelihood of the observations on $\varepsilon_{t}$ is given by

$$
L=-\frac{1}{2} \sum_{t=1}^{T}\left(n \log (2 \pi)+\log \left|D_{t} R_{t} D_{t}\right|+\varepsilon_{t}^{\prime} D_{t}^{-1} R_{t}^{-1} D_{t}^{-1} \varepsilon_{t}\right)
$$

Since $u_{t}=\varepsilon_{t} / \sqrt{h_{t}}=D_{t}^{-1} \varepsilon_{t}$, the log-likelihood function can be rewritten as follows:

$$
L=-\frac{1}{2} \sum_{t=1}^{T}\left(n \log (2 \pi)+2 \log \left|D_{t}\right|+\log \left|R_{t}\right|+u_{t}^{\prime} R_{t}^{-1} u_{t}\right)
$$

Note that a conditional variance term can be added into the mean equation to control for the risk-return tradeoffs in previous works. However, the majority of these studies found evidence of insignificant impact of conditional volatility on stock returns. Lundblad (2007) studied the same issue over the period from 1802 to today and concluded that the meanvariance tradeoffs are only positively significant over a long-term horizon. Accordingly, we intentionally do not model the in-mean effect of conditional volatility because we focus on a short-run comovement between stock and bond markets ${ }^{1}$.

\subsection{Detecting structural breaks in cross-market comovements}

Over the last three decades, emerging markets in Latin American region have experienced significant reforms on capital markets and various periods of financial turbulences such as the Mexican crisis in 1994-1995, the Brazilian crisis in 1998 and Argentinean crisis in 2001. The cross-market comovements might be subjected to structural changes. Intuitionally, a higher degree of financial openness can strengthen the relationship between international stock markets, whereas the depth of financial crises seriously affected a country's economic and financial structure, which in turn leads to changes in the nature of its comovements with other countries. Since the changes in the cross-market comovements

\footnotetext{
${ }^{1}$ We effectively attempted to estimate our model with the in-mean volatility effects in the return generating processes and the results are consistent with our intuition and Lundblad (2007)'s findings.
} 
will impact the coordination of two countries' policymakers and the actions of portfolio managers, it is important to question the issue of structural changes.

In this study we refer to the bilateral dynamic conditional correlation as measure of cross-market comovements and use the Bai and Perron (2003)'s testing procedure to investigate whether the time-varying cross-market comovements contain structural breaks. The idea here is to determine the number and location of breaks in a linear regression model.

Suppose there are $m$ breaks $\left(n_{1}, \ldots, n_{m}\right)$ in the time-path of the dependant variable, the problem of dating structural breaks turns to find the breakpoints $\left(\tilde{n}_{1}, \ldots, \tilde{n}_{m}\right)$ that minimize the objective function:

$$
\left(\tilde{n}_{1}, \ldots, \tilde{n}_{m}\right)=\arg \min _{\left(n_{1}, \ldots, n_{m}\right)} \operatorname{RSS}_{n}\left(n_{1}, \ldots, n_{m}\right)
$$

In this formula, $R S S_{n}$ is the resulting residual sum of squares based on the $m$ regressions as shown by the following equation:

$$
y_{t}=\beta x_{t}^{\mathrm{T}}+\varepsilon_{t} \quad(t=1, \ldots, n)
$$

where $y_{t}$ is the estimated conditional correlation series at the time $t, x_{t}=\left(1, y_{t-1}\right)^{\mathrm{T}}$ is the $(2 \times 1)$ vector of observations of the independent variables with the first component equal to unity, $\beta$ is the $(2 \times 1)$ vector of regression coefficients, and $\varepsilon_{t}$ is assumed to be $\operatorname{iid}\left(0, \sigma^{2}\right)$.

The structural stability tests as presented above are concerned with testing the null hypothesis of 'no structural break' against the alternative that the regression coefficients vary over time. The breakpoint selection procedure is based on the Bayesian Information Criteria (BIC). Empirically, we set the maximum number of optimal breaks to be 5 and run the test. However, if the effective number of breaks is equal to 5, a higher number of breaks will be automatically chosen so that the testing procedure captures all possible breakpoints. The optimal number of breaks corresponds to the one with the lowest BIC score. 


\section{EMPIRICAL RESULTS}

This section reports and interprets the results obtained from the estimation of our empirical model. First, we present the estimation results of the empirical model and investigate the dynamics of conditional correlations between markets. Second, we take a close look into the results from structural break tests over the estimation period. Finally, as a checking exercise, we investigate whether our results validate or not the purpose that the comovement between stock markets is larger in crisis times.

\subsection{Estimation Results}

Table 2 contains parameter estimates and a number of diagnostic tests for DCC-GARCH model. The coefficients relating the return series to the one-lag local and world returns (Panel A) are insignificant, except for Colombia. The ARCH coefficients and GARCH coefficients reported in panel B are significant for all countries, except Venezuela. This is on line with previous results in the literature. The coefficients $\alpha$ are relatively small in size, which indicates that conditional volatility does not change very rapidly. However, the coefficients $\beta$ are large, indicating gradual fluctuations over time. In addition, the estimates coefficients $\alpha$ and $\beta$ satisfy the stationary conditions for all the variance and covariance processes.

\section{[Please insert Table 2 about here]}

Diagnostics of standardized residuals are provided in panel $\mathrm{C}^{2}$ One can remark that the indexes of kurtosis are often lower than those for the returns. However, the Bera-Jarque test statistics for normality indicates that the unconditional distribution of the conditionally normal GARCH process is not sufficiently fat-tailed to accommodate the excess kurtosis in the data. This result justifies the use of the QML procedures. We also compute the LungBox statistic to test the null hypothesis of absence of autocorrelation and the Engle (1982)'s test of absence of ARCH effects. The results indicate that the DCC-GARCH specification we use is flexible enough to capture the dynamics of the conditional covariance matrix.

\section{[Please insert Figure 1 about here]}

\footnotetext{
${ }^{2}$ In the multivariate framework, the joint standardized residuals are given by $\varepsilon_{t}^{s}=H_{t}^{-1 / 2} \varepsilon_{t}$.
} 
Dynamic conditional correlations within Latin American emerging markets and with the world market are plotted in Figure 1. These correlations are relatively low, 21.54\% on average. The average time-varying correlations are quite similar to the unconditional correlations reported in Table 1. However, the conditional correlations vary considerably over time and from a couple of countries to another. The average of correlations between the studied Latin American markets and the world market is $25.30 \%$. The average of correlations within the studied Latin American markets is only 20.04\%. The highest conditional correlation is between Mexico and Chile (42.75\%) and the lowest one is between Argentina and Colombia (6.76\%). Interestingly, it is also observed that the evolution of these correlations witnesses some periods on negative values. This should mean high diversification gains from investing in Latin American emerging countries.

The most interesting patterns found is that there is a clear upward trend in correlation from 1994 and onwards as a result of market liberalization and increased globalization. The lowest average correlation between all studied markets can be found between 1985 and 1993. Interestingly, it can be seen that there are sudden increases in conditional correlation following the Asian and Brazilian financial crises in 1997-1998 and, to less extent, the stock market crash in 1987 and the Latin American markets crises in 1994 and 2001. The increased correlation in period of crises may be a symptom of international contagion. This point will be further investigated in section 4.3.

\subsection{Do Structural Breaks Exist?}

In this section, we investigate whether any structural change has occurred in conditional correlations between studied Latin American emerging markets and the world market over the estimation period. We apply the Bai and Perron (2003)'s testing procedure to detect and date the structural breakpoints in our conditional correlations indices. In principle, a model's optimal number of breakpoints $(m)$ is the one associated with the minimum BIC. Figure 2 plots the BIC for models with $m$ breakpoints for our sample markets. The selected optimal breakpoints for each market and their $95 \%$ confidence intervals are reported in Table 3 .

[Please insert Figure 2 about here] 


\section{[Please insert Table 3 about here]}

The null hypothesis of stability is rejected for all the studied markets since the BaiPerron's test detects breakpoints for the six markets. For Argentina, five significant breakpoints are obtained and for all the other studied countries four breakpoints are detected.

If we compare the estimated break dates in conditional correlations reported in Table 3 to the liberalization dates in Table 4, we find that the official liberalization dates fall into the $95 \%$ confidence intervals for the estimated break date in three markets: Brazil, Colombia and Mexico. As markets open up and become more liberalized and integrated with the rest of the world, one may expect that the correlation of a country with the world market increases. Our results confirm partially this opinion.

In Chile, the date where the first ADR was introduced is bounded by the $95 \%$ confidence interval of the first break date. In Argentina and Venezuela, none of the estimated break dates is related to market liberalization events. Finally, note the break date observed in all studied markets following the Asian and Brazilian financial crises in 1997-1998.

\section{[Please insert Table 4 about here]}

To sum up, major stock market events such as financial market liberalizations, ADR introduction and crisis have significant impacts on the Latin American emerging markets comovements. In general, the conditional correlations between these markets have increased in recent years as a result of the lifting of barriers.

\subsection{Is the cross-market comovement higher in crisis period?}

The majority of past studies claim that the comovement of stock markets is stronger during the crisis period than during the normal or tranquil ones. In this paper we test this purpose through investigating the differences in the level of conditional correlations between two 60-month subperiods. The first sub-period is a normal one starting in December 1989 and terminating in November 1994, whereas the crisis subperiod covers the period from December 1994 through November 1999 which contains the 1994-1995 Mexican and the 1997 Asian crises. The Asian crisis is included in our analysis because it spreads over quickly to Brazil causing the Brazilian crisis in 1998, and thus to the whole Latin American region. 
Our method is simple and consists of calculating both the mean and the variance of the conditional correlation coefficients over two subperiods. A one-tail parametric test, called Z-test, is then applied to compare the means between two subsamples. Concretely, we test the null hypothesis that the mean of the conditional correlations in the crisis subperiod is equal to that in the tranquil period against the one-sided alternative that it is higher than the later one. The empirical $z$-statistic, assumed to follow a standard normal distribution under the null hypothesis is determined by the following expression: $z=(\bar{x}-m) \div(\sigma / \sqrt{n})$, where $\bar{x}$ refers to the mean of the crisis period, $m$ is set to be the mean of the tranquil period, $\sigma$ refers to the standard deviation of the crisis period and $n$ is equal to 60 .

\section{[Please insert Table 5 about here]}

Table 5 reports the obtained results. Overall, we observe that the inter-market comovements were significantly higher during the crisis period than during the tranquil period. The linkages between Latin American markets and the world market index follow the same schema, except for the case of Colombia where there was a significant decrease in correlation coefficient with the world market. Therefore, we are not able to reject the preposition according to which stock markets tend to move much more together during the crisis time than during a normal time.

\section{DISCUSSIONS AND FUTURE EXTENSIONS}

The purpose of this paper was to investigate empirically the comovements between Latin American emerging markets et between these markets and the World stock market over the 1985-2005 period. As pointed out by our empirical findings, there were upward trends in conditional correlations since 1994 and onwards in all sample markets. This evidence is strengthened by the fact that the cross-market correlation coefficients exceed $60 \%$ in recent years in many cases. As far as the issues of international market integration and portfolio diversification are concerned, there is still further room for global investors to get in Latin American emerging countries due to their low average correlations. At the same time, it is worth noting that the market liberalization process in selected emerging stock markets and 
the resulting increased globalization do increase the comovements of capital markets around the world, and thus reduce significantly the international diversification benefits. However, the presence of frequent structural breaks in the time-path of cross-market correlation series as evidenced by our results typically adds that a reassessment of stock market comovements is necessary for implementing any investment strategy in Latin American, and so saying as a follow-up of major stock market events. Last but not least, higher comovement of sample stock markets in times of crisis can be considered as evidences of contagion effects highlighted by a number of previous studies.

For future perspectives, this study can be extended in some ways. First, the same methodology presented in this study can be applied to the issue of cross-country stock-bond return comovements to explore the relationships in different asset classes both at the country and international levels. This kind of study is of great importance because any portfolio optimization strategy hinges on the concept of correlation. Second, the empirical model presented in this paper is suitable to the investigation of the determinants of stock market comovements, of which macroeconomic announcements and economic and financial integration factors might be relevant candidates. Such research allows for example to determine the roots of stock market comovements and to answer the question of whether they result from world market integration or global bubbles. 


\section{REFERENCES}

Bae, K., Karolyi, G.A., Stulz, R.M., (2003), 'A New Approach to Measuring Financial Contagion', Review of Financial Studies, 16, 717-763.

Bai, J., Perron, P. (1998), 'Estimating and Testing Linear Models with Multiple Structural Changes', Econometrica, 66, 47-78.

Bai, J., Perron, P. (2003), 'Computation and Analysis of Multiple Structural Change Models', Journal of Applied Econometrics, 18, 1-22.

Bekaert, G., and Harvey, C.R. (1995), 'Time-Varying World Market Integration', Journal of Finance, 50, 403-444.

Bekaert, G., Harvey, C.R. (1997), 'Emerging Equity Market Volatility', Journal of Financial Economics, 43, 29-78.

Bekaert, G., Harvey, C.R. (2000), 'Foreign Speculators and Emerging Equity Markets', Journal of Finance, 55, 565-613.

Bekaert, G., Hodrick, R.J., Zhang, X. (2005), 'International Stock Return Comovements', Columbia University Working Paper.

Bollerslev, T. (1986), 'Generalized Autoregressive Conditional Heteroscedasticity', Journal of Econometrics, 31, 307-327.

Bollerslev, T., Wooldridge, J.M. (1992), 'Quasi Maximum Likelihood Estimation and Inference in Dynamic Models with time Varying Covariances', Econometric Review, 11, 143 172.

Carrieri, F., Errunza, V., and Hogan, K. (2005), 'Characterizing World Market Integration through Time', McGill University Working Paper.

Chen, G-M., Firth, M., Rui, O.M. (2002), 'Stock Market Linkages: Evidence from Latin America', Journal of Banking \& Finance, 26, 1113-1141.

Choudry, T. (1997), 'Stochastic Trends in Stock Prices: Evidence from Latin American Markets', Journal of Macroeconomics, 19, 285-304.

Christofi, A., Pericli, A. (1999), 'Correlation in Price Changes and Volatility of Major Latin American Stock Markets', Journal of Multinational Financial Management, 9, 79-93.

Engle, R.F, Granger, C.W.J. (1987), 'Co-integration and Error Correction: Representation, Estimation and Testing', Econometrica, 55, 251-276.

Engle, R.F. (1982), 'Autoregressive Conditional Heteroscedasticity with Estimates of the Variance of UK Inflation', Econometrica, 50, 987-1008.

Engle, R.F. (2002), 'Dynamic Conditional Correlation: a New Simple Class of Multivariate GARCH Models', Journal of Business and Economic Statistics, 20, 339-350.

Erb, C., Harvey, C.R., Viskanta T. (1994), 'Forecasting International Equity Correlations', Financial Analysts Journal (November/December), 32-45. 
Errunza, V. (1977), 'Gains from Portfolio Diversification into less Developed Countries' Securities', Journal of International Business Studies, 52, 83-99.

Eun, C.S., Shim, S. (1989), 'International Transmission of Stock Market Movements', Journal of Financial \& Quantitative Analysis, 24, 241-256.

Forbes, K., Rigobon, R. (2002), 'No Contagion, only Interdependence: Measuring Stock Market Comovements', Journal of Finance, 57, 2223-2261.

Fujii, E. (2005), 'Intra and Inter-regional Causal Linkages of Emerging Stock Markets: Evidence from Asia and Latin America In and Out of Crises', International Financial Markets, Institutions and Money, 15, 315-342.

Gerard, B., Thanyalakpark, K., Batten, J.A. (2003), 'Are the East Asian markets integrated? Evidence from the ICAPM', Journal of Economics and Business, 55, 585-607.

Geweke, J., (1982), 'Measurement of Linear Dependence and Feedback between Multiple Time Series', Journal of the American Statistical Association, 77, 304-313.

Gilmore, C.G., Lucey, B.M., McManus, G.M. (2006), 'The Dynamics of Central European Equity Market Comovements', Quarterly Review of Economics and Finance, forthcoming.

Granger, C.J. (1969), 'Investigating Causal Relationships by Econometrics Models and Cross Spectral Methods', Econometrica, 37, 425-435.

Grubel, H. (1968), 'Internationaly diversified portfolios: welfare gains and capital flows', American Economic Review, 58, 1299-1314.

Hamao, Y., Masulis, R.W., Ng, V. (1990), 'Correlations in Price Changes and Volatility across International Markets', Review of Financial Studies, 3, 281-307.

Harvey, C.R. (1995), 'Predictable Risk and Returns in Emerging Markets', Review of Financial Studies, 8, 773-816.

Hsin, C-W. (2004), 'A Multilateral Approach to Examining the Comovements among Major World Equity Markets', International Review of Financial Analysis, 13, 433-462.

Jarque, C.M., Bera, A.K. (1980), 'Efficient Tests for Normality, Homoscedasticity and Serial Independence of Regression Residuals', Economics Letters, 6, 255-259.

Jayasuriya, S. (2005), 'Stock Market Liberalization and Volatility in the Presence of Favorable Market Characteristics and Institutions', Emerging Markets Review, 6, 170-191.

Johnson, R., Soenen, L. (2003), 'Economic Integration and Stock Market Comovement in the Americas', Journal of Multinational Financial Management, 13, 85-100.

Johnson, R., Soenen, L. (2003), 'Economic Integration and Stock Market Comovement in the Americas', Journal of Multinational Financial Management, 13, 85-100.

Karolyi, G.A. (1995), 'A Multivariate GARCH Model of International Transmissions of Stock Returns and Volatility: The case of the United States and Canada', Journal of Business and Economic Statistics, 13, 11-25. 
Karolyi, G.A., Stulz, R.M. (1996), 'Why Do Markets Move Together? An Investigation of U.S.-Japan Stock Return Comovements', Journal of Finance, 51, 951-986.

Kim, E.H., Singal, V. (2000), 'Stock Market Openings: Experience of Emerging Economies’, Journal of Business, 73, 25-66.

Lessard, D. (1973), 'World, National and Industry Factors in Equity Returns', Journal of Finance, 29, 379-391.

Lintner, J. (1965), 'The Valuation of Risk Assets and the Selection of Risky Investment in Stock Portfolio and Capital Budgets', Review of Economics and Statistics, 47, 13-37.

Longin, F., Solnik, B. (1995), 'Is the Correlation in International Equity Returns Constant: 1970-1990?', Journal of International Money \& Finance, 14, 3-26.

Lundblad, C. (2007), 'The Risk Return Tradeoff in the Long Run: 1836-2003', Journal of Financial Economics, 85, 123-150.

Markowitz, H. (1952), 'Portfolio Selection', Journal of Finance, 7, 77-91.

Miles, W. (2002), 'Financial Deregulation and Volatility in Emerging Equity Markets', Journal of Economic Development, 27, 113-126.

Morana, C., Beltratti, A. (2006), 'Comovements in International Stock Markets', Journal of International Financial Markets, Institutions and Money, forthcoming.

Richards, A.J. (1995), 'Comovements in National Stock Market Returns: Evidence of Predictability, but not Cointegration', Journal of Monetary Economics, 36, 631-654.

Sharpe, W.F. (1964), 'Capital Asset Prices: A Theory of Market Equilibrium under Conditions of Risk', Journal of Finance, 19, 425-442.

Sims, C.A. (1980), 'Macroeconomics and Reality', Econometrica, 48, 1-48.

Syriopoulos, T. (2007), 'Dynamic Linkages between Emerging European and Developed Stock Markets: Has the EMU any Impact?', International Review of Financial Analysis, 16, 41-60. 
Table 1

Descriptive Statistics

Panel A: Summary Statistics

\begin{tabular}{|c|c|c|c|c|c|c|c|}
\hline & Argentina & Brazil & Chile & Colombia & Mexico & Venezuela & World \\
\hline $\begin{array}{l}\text { Mean } \\
\text { (\% per month) }\end{array}$ & 1.384 & 1.095 & 1.968 & 1.771 & 1.700 & 0.685 & 0.929 \\
\hline $\begin{array}{l}\text { Std-Deviation } \\
\text { (\% per month) }\end{array}$ & 18.724 & 16.570 & 7.472 & 8.355 & 12.276 & 13.867 & 4.281 \\
\hline Skewness & $0.379^{* *}$ & $-0.639^{*}$ & $-0.338^{* *}$ & $0.493^{*}$ & $-2.425^{*}$ & $-0.921^{*}$ & $-0.767^{*}$ \\
\hline Kurtosis & $10.265^{*}$ & $3.146^{*}$ & $1.187^{*}$ & $1.698^{*}$ & $14.725^{*}$ & $4.747^{*}$ & $1.969^{*}$ \\
\hline JB & $1090.425^{+}$ & $118.673^{+}$ & $19.219^{+}$ & $39.669^{+}$ & $2473.406^{+}$ & $266.794^{+}$ & $64.107^{+}$ \\
\hline $\mathbf{Q}(\mathbf{1 2})$ & 15.571 & 10.718 & $22.025^{++}$ & $44.915^{+}$ & $36.192^{+}$ & 7.782 & 13.802 \\
\hline $\operatorname{ARCH}(12)$ & $49.042^{+}$ & $25.773^{++}$ & 15.182 & $33.243^{+}$ & $50.375^{+}$ & 6.901 & 9.169 \\
\hline \multicolumn{8}{|c|}{ Panel B: Autocorrelations } \\
\hline Retard & Argentina & Brazil & Chile & Colombia & Mexico & Venezuela & World \\
\hline 1 & -0.054 & -0.007 & $0.198^{*}$ & $0.353^{*}$ & $0.284^{*}$ & -0.005 & 0.0411 \\
\hline 2 & -0.063 & 0.022 & -0.045 & $0.102^{* * *}$ & -0.074 & $0.107^{* * *}$ & -0.033 \\
\hline 3 & 0.072 & -0.087 & -0.096 & -0.004 & $-0.155^{*}$ & 0.023 & 0.0213 \\
\hline 4 & -0.097 & -0.061 & 0.009 & -0.014 & -0.079 & -0.022 & -0.056 \\
\hline 5 & -0.074 & -0.011 & 0.077 & $0.108^{* * *}$ & 0.049 & 0.046 & 0.082 \\
\hline 6 & 0.089 & 0.003 & -0.003 & 0.088 & -0.079 & -0.015 & 0.0245 \\
\hline
\end{tabular}

Panel C: Unconditional correlations of $r_{i t}$ (in percentage)

\begin{tabular}{lccccccc}
\hline \hline & Argentina & Brazil & Chile & Colombia & Mexico & Venezuela & World \\
\hline Argentina & 1.00 & 11.171 & 20.053 & 7.001 & 26.782 & 14.571 & 11.154 \\
Brazil & & 1.00 & 31.724 & 16.317 & 20.995 & 2.220 & 33.820 \\
Chile & & & 1.00 & 23.777 & 43.345 & 9.518 & 35.762 \\
Colombia & & & & 1.00 & $13 . .765$ & 20.772 & 14.942 \\
Mexico & & & & & 1.00 & 9.164 & 40.883 \\
Venezuela & & & & & & 1.00 & 8.002 \\
MSCI World & & & & & & & 1.00 \\
\hline
\end{tabular}

Notes: The test for Kurtosis coefficient has been normalized to zero. JB is the Jarque-Bera test for normality based on excess skewness and Kurtosis. Q(12) is the Ljung-Box test for autocorrelation of order 12.ARCH is the Engle (1982)'s test for conditional heteroscedasticity. *,** and $* * *$ indicate significance of coefficients at the $1 \%, 5 \%$ and $10 \%$ respectively.,+++ and +++ indicate rejection of the null hypotheses of no autocorrelation, normality and homocedasticity at the $1 \%, 5 \%$ and $1 \%$ levels of significance respectively for statistical tests. 
Table 2

Estimation results

Panel A - parameter estimates-mean equations

\begin{tabular}{lccccccc}
\hline \hline & Argentina & Brazil & Chile & Colombia & Mexico & Venezuela & World \\
\hline$\delta_{0}$ & $0.024^{*}$ & $0.023^{*}$ & $0.018^{*}$ & $0.010^{* * *}$ & $0.020^{*}$ & 0.001 & $0.010^{*}$ \\
& $(0.009)$ & $(0.010)$ & $(0.005)$ & $(0.005)$ & $(0.007)$ & $(0.013)$ & $(0.003)$ \\
$\delta_{1}$ & 0.030 & 0.0299 & 0.041 & $0.283^{*}$ & 0.089 & 0.070 & -0.008 \\
& $(0.086)$ & $(0.074)$ & $(0.061)$ & $(0.062)$ & $(0.063)$ & $(0.092)$ & $(0.067)$ \\
$\delta_{2}$ & -0.163 & -0.048 & 0.122 & $0.351^{*}$ & -0.017 & 0.093 & - \\
& $(0.285)$ & $(0.287)$ & $(0.108)$ & $(0.106)$ & $(0.143)$ & $(0.221)$ & \\
\hline
\end{tabular}

Panel B: parameter estimates-GARCH process

\begin{tabular}{lccccccc}
\hline \hline & Argentina & Brazil & Chile & Colombia & Mexico & Venezuela & World \\
\hline$\varpi_{0}$ & 0.001 & 0.0010 & 0.000 & $0.001^{* * *}$ & $0.001^{* * * *}$ & $0.019^{*}$ & 0.000 \\
& $(0.001)$ & $(0.000)$ & $(0.000)$ & $(0.000)$ & $(0.001)$ & $(0.006)$ & $(0.000)$ \\
$\varpi_{1}$ & $0.218^{* *}$ & $0.167^{*}$ & 0.045 & $0.145^{*}$ & $0.231^{*}$ & 0.221 & $0.079^{*}$ \\
& $(0.110)$ & $(0.057)$ & $(0.031)$ & $(0.042)$ & $(0.072)$ & $(0.264)$ & $(0.034)$ \\
$\varpi_{2}$ & $0.771^{*}$ & $0.811^{*}$ & $0.876^{*}$ & $0.703^{*}$ & $0.695^{*}$ & -0.097 & $0.885^{*}$ \\
& $(0.085)$ & $(0.041)$ & $(0.058)$ & $(0.089)$ & $(0.059)$ & $(0.103)$ & $(0.039)$ \\
\hline$\alpha$ & $0.033^{*}$ & & & & & & \\
$\beta$ & $(0.006)$ & & & & & & \\
& $0.961^{*}$ & & & & & & \\
& $(0.005)$ & & & & & & \\
\hline \hline
\end{tabular}

Panel C - Robust tests for model standardized residuals

\begin{tabular}{cccccccc}
\hline \hline & Argentina & Brazil & Chile & Colombia & Mexico & Venezuela & World \\
\hline Mean & -0.052 & -0.075 & -0.020 & -0.001 & -0.033 & 0.014 & -0.022 \\
Std-Deviation & 1.033 & 1.018 & 1.016 & 0.967 & 1.038 & 0.970 & 0.996 \\
Skewness & $0.601^{*}$ & $-0.665^{*}$ & $-0.318^{* *}$ & 0.288 & -1.377 & $-0.998^{*}$ & $-0.806^{*}$ \\
Kurtosis & $3.951^{*}$ & $2.134^{*}$ & $1.089^{*}$ & $1.248^{*}$ & $4.925^{*}$ & $4.599^{*}$ & $2.552^{*}$ \\
JB & $174.803^{*}$ & $64.820^{*}$ & $16.308^{*}$ & $19.356^{*}$ & $326.38^{*}$ & $257.691^{*}$ & $93.397^{*}$ \\
Q(12) & 2.937 & 6.654 & 17.235 & 9.496 & $18.974^{* * *}$ & 9.281 & 13.286 \\
ARCH(12) & 6.462 & 10.262 & 14.842 & 5.303 & 3.708 & 7.628 & 5.804 \\
\hline \hline
\end{tabular}

Notes: Bollerslev and Wooldridge (1992)'s robust standard errors are given in parentheses. $\varpi_{0}, \varpi_{1}$ and $\varpi_{2}$ refer to the parameters of a $\operatorname{GARCH}(1,1)$ process. The test for Kurtosis coefficient has been normalized to zero. JB is the Jarque-Bera test for normality based on excess skewness and Kurtosis. Q(12) is the Ljung-Box test for autocorrelation of order 12. ARCH is the Engle (1982)'s test for conditional heteroscedasticity. *, ** and *** indicate significance of coefficients at the $1 \%, 5 \%$ and $10 \%$ respectively.,+++ and +++ indicate rejection of the null hypotheses of no autocorrelation, normality and homocedasticity at the $1 \%, 5 \%$ and $1 \%$ levels of significance respectively for statistical tests. 
Table 3

Results of the Bai-Perron's test for multiple structural breakpoints in the conditional correlations with the world market

\begin{tabular}{|c|c|c|c|}
\hline Market & Number of breakpoints & Estimated break dates & $\begin{array}{l}95 \% \text { confidence intervals } \\
\text { for break dates }\end{array}$ \\
\hline Argentina & 5 & $\begin{array}{l}\text { 1989:07 } \\
\text { 1992:07 } \\
\text { 1995:07 } \\
\text { 1998:09 } \\
\text { 2002:08 }\end{array}$ & $\begin{array}{l}\text { [1989:05-1989:08] } \\
{[1992: 05-1992: 09]} \\
{[1995: 06-1995: 09]} \\
{[1998: 07-1998: 10]} \\
{[2002: 07-2003: 01]}\end{array}$ \\
\hline Brazil & 4 & $\begin{array}{l}1988: 02 \\
\text { 1991:03 } \\
\text { 1997:11 } \\
\text { 2001:10 }\end{array}$ & $\begin{array}{l}\text { [1988:01-1990:03] } \\
{[1991: 01-1991: 06]} \\
{[1997: 10-1997: 12]} \\
{[2001: 09-2001: 12]}\end{array}$ \\
\hline Chile & 4 & $\begin{array}{l}\text { 1990:02 } \\
\text { 1994:04 } \\
\text { 1998:09 } \\
\text { 2001:10 }\end{array}$ & $\begin{array}{l}\text { [1989:12-1990:04] } \\
{[1994: 03-1994: 08]} \\
{[1998: 08-1998: 10]} \\
{[2001: 09-2002: 02]}\end{array}$ \\
\hline Colombia & 4 & $\begin{array}{l}\text { 1990:09 } \\
\text { 1995:03 } \\
\text { 1998:09 } \\
\text { 2002:08 }\end{array}$ & $\begin{array}{l}{[1988: 02-1992: 01]} \\
{[1994: 12-1995: 06]} \\
{[1998: 08-1998: 10]} \\
{[2002: 07-2002: 11]}\end{array}$ \\
\hline Mexico & 4 & $\begin{array}{l}\text { 1988:02 } \\
\text { 1992:02 } \\
\text { 1995:09 } \\
\text { 1998:09 }\end{array}$ & $\begin{array}{l}{[1987: 12-1989: 07]} \\
{[1991: 121992: 08-]} \\
{[1994: 02-1995: 12]} \\
{[1998: 08-1998: 10]}\end{array}$ \\
\hline Venezuela & 4 & $\begin{array}{l}\text { 1989:11 } \\
\text { 1992:11 } \\
\text { 1997:07 } \\
\text { 2000:07 }\end{array}$ & $\begin{array}{l}{[1989: 06-1989: 12]} \\
{[1992: 10-1993: 04]} \\
{[1997: 04-1997: 08]} \\
{[2000: 06-2004: 02]}\end{array}$ \\
\hline
\end{tabular}

Notes: The breakpoint selection procedure in the works of Bai and Perron (1998,2003) is based on the Bayesian Information Criteria (BIC). First, we arbitrarily set the maximum number of breaks to be 5. If the effective number of breaks is equal to 5, a higher number of breaks will be chosen so that the testing procedure captures all possible breakpoints. In principle, a model's optimal number of breakpoints is the one associated with the minimum BIC. For the countries considered in this present study, none of the volatility series has more than 5 breakpoints. 
Table 4

Stock market liberalization dates

\begin{tabular}{l|c|c|c|c}
\hline \hline Market & $\begin{array}{c}\text { Official dates of } \\
\text { liberalization }\end{array}$ & $\begin{array}{c}\text { Date of the first } \\
\text { ADR introduction }\end{array}$ & $\begin{array}{c}\text { Date of the first Coun- } \\
\text { try Fund introduction }\end{array}$ & $\begin{array}{c}\text { Date of the structural } \\
\text { break in the US capital } \\
\text { flows }\end{array}$ \\
\hline \hline Argentina & $11-1989$ & $08-1991$ & $10-1991$ & $04-1993$ \\
Brazil & $05-1991$ & $01-1992$ & $10-1987$ & $06-1986$ \\
Chile & $01-1992$ & $03-1990$ & $09-1989$ & $01-1988$ \\
Colombia & $02-1991$ & $12-1992$ & $05-1992$ & $08-1993$ \\
Mexico & $05-1989$ & $01-1989$ & $06-1981$ & $05-1990$ \\
Venezuela & $01-1990$ & $08-1991$ & NA & $02-1994$ \\
\hline \hline
\end{tabular}

Notes: all the dates reported in this table are derived from Bekaert and Harvey (2000) 
Table 5

Changes in conditional correlations: tranquil versus crisis periods

\begin{tabular}{|l|r|r|r|r|r|r|}
\hline \hline & \multicolumn{1}{|l}{ Argentina } & \multicolumn{1}{l|}{ Brazil } & \multicolumn{1}{l|}{ Chile } & \multicolumn{1}{l|}{ Colombia } & \multicolumn{1}{l|}{ Mexico } & Venezuela \\
\hline Brazil & 0.323 & & & & & \\
& $(23.233)$ & & & & & \\
\hline Chile & 0.252 & 0.187 & & & & \\
& $(26.172)$ & $(37.699)$ & & & & \\
\hline Colombia & 0.120 & 0.073 & 0.140 & & & \\
& $(18.622)$ & $(14.899)$ & $(5.433)$ & & & \\
\hline Mexico & 0.237 & 0.304 & 0.108 & 0.018 & & \\
& $(34.825)$ & $(41.987)$ & $(15.392)$ & $(3.413)$ & & \\
\hline Venezuela & 0.058 & 0.292 & 0.302 & 0.080 & 0.123 & \\
& $(14.818)$ & $(23.158)$ & $(51.614)$ & $(4.972)$ & $(23.158)$ & \\
\hline MSCI World & 0.318 & 0.097 & 0.203 & -0.031 & 0.065 & 0.210 \\
& $(26.044)$ & $(14.722)$ & $(19.622)$ & $(-4.546)$ & $(14.547)$ & $(14.918)$ \\
\hline \hline
\end{tabular}

Notes: this table provides the differences in the means of conditional correlation coefficients between the 60month crisis period and the 60-month tranquil period. The number in parenthesis refers to the empirical $z$ statistics. The critical values of $z$ at $95 \%$ and $99 \%$ confidence levels assuming normality of the series under consideration are equal to 1.96 and 2.33 respectively. 


\section{Figure 1}

\section{Dynamic Conditional Correlations}

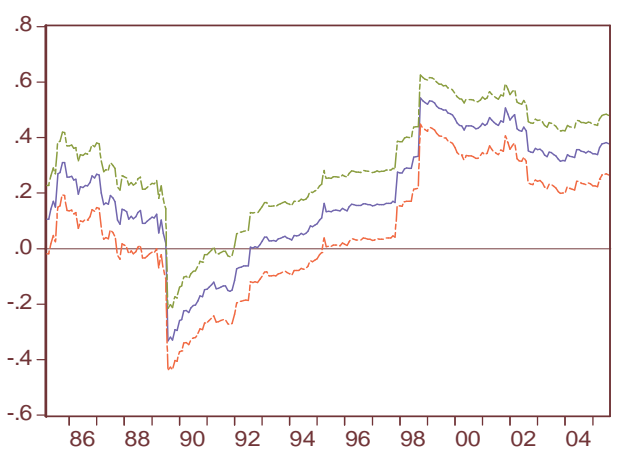

a- Argentina-Brazil

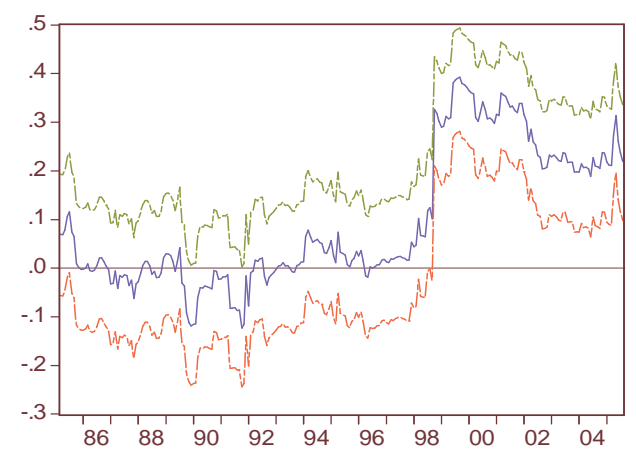

c-Argentina-Colombia

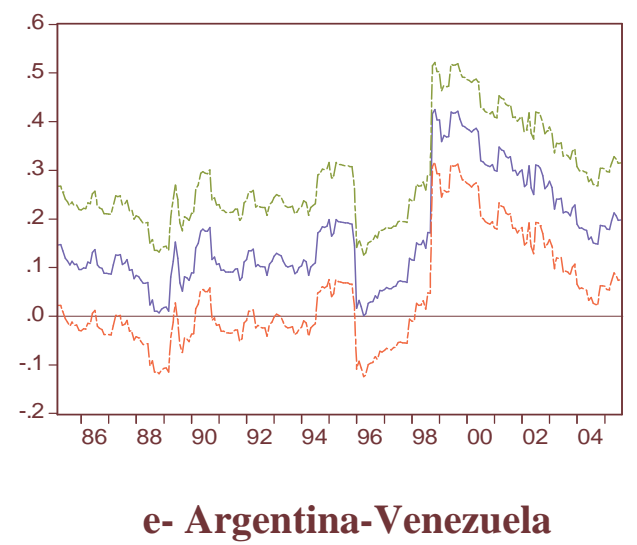

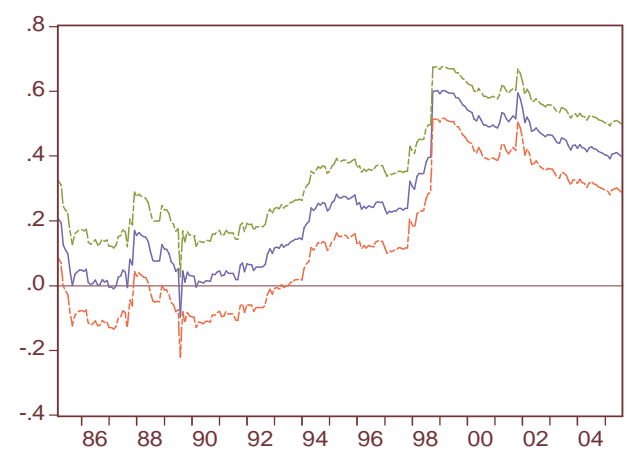

b- Argentina-Chile

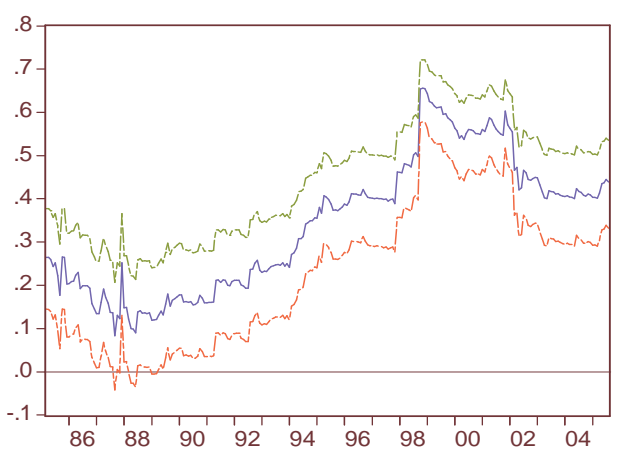

d- Argentina-Mexio

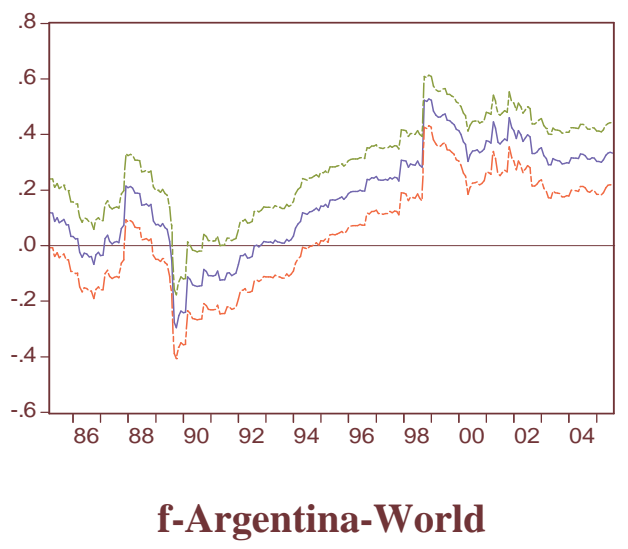




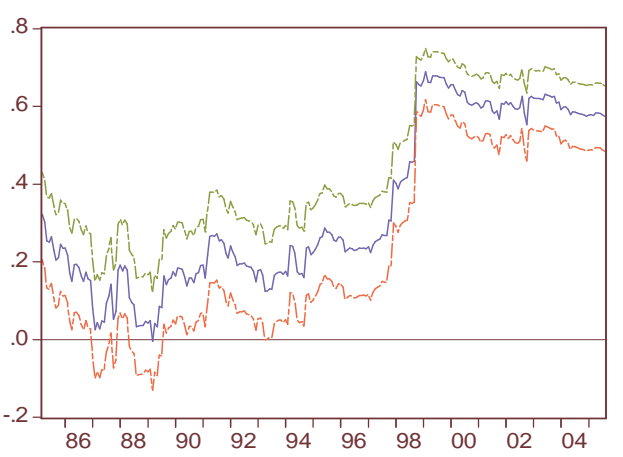

g- Brazil-Chile

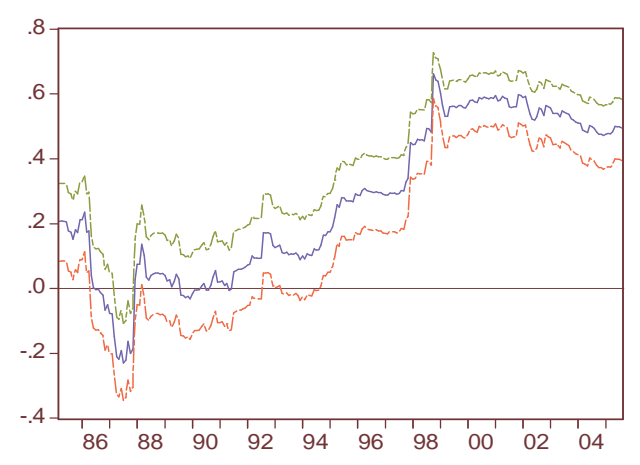

i- Brazil-Mexico

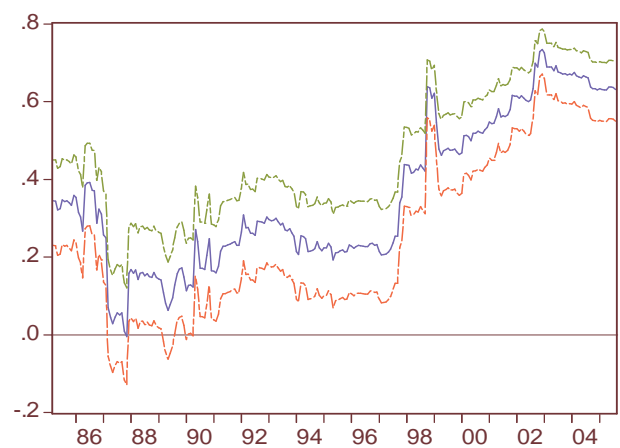

k- Brazil-World

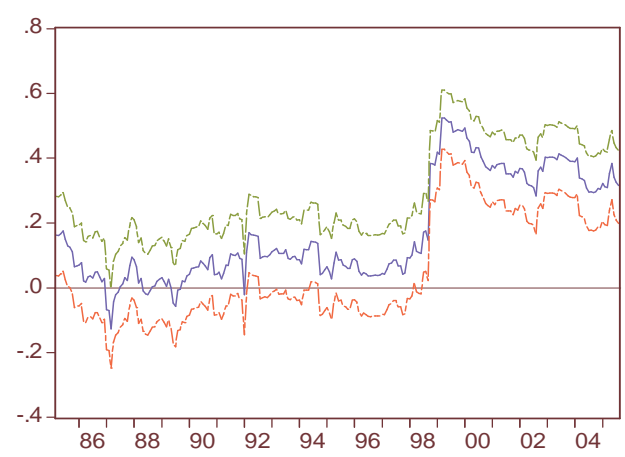

h-Brazil-Colombia

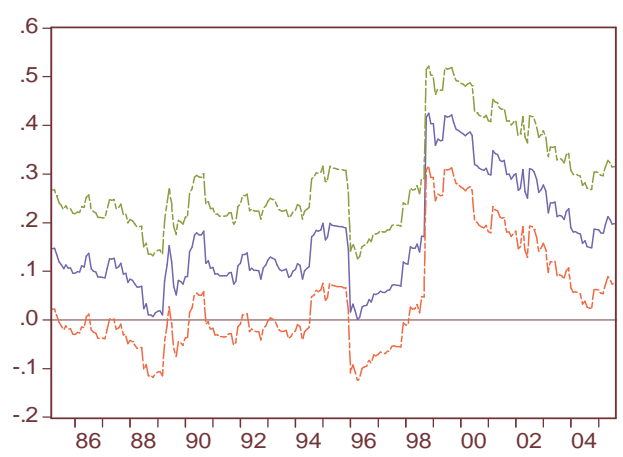

j- Brazil-Venezuela

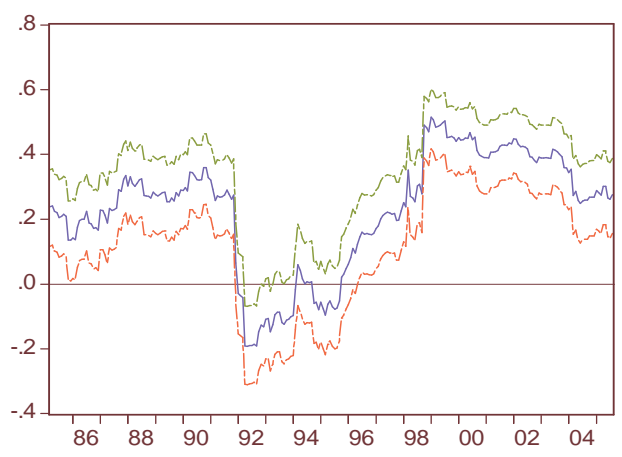

l-Chile-Colombia 


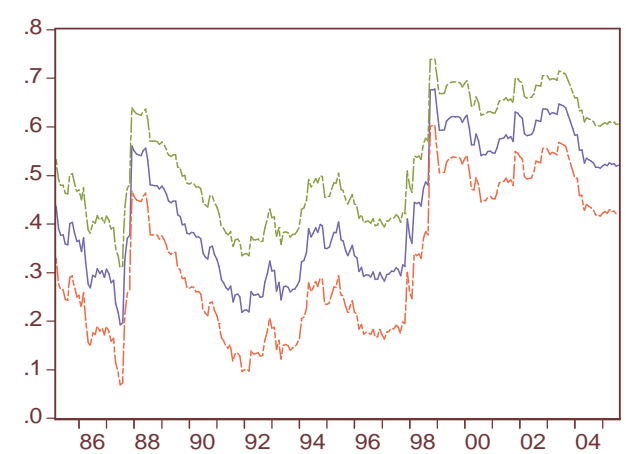

m-Chile-Mexico

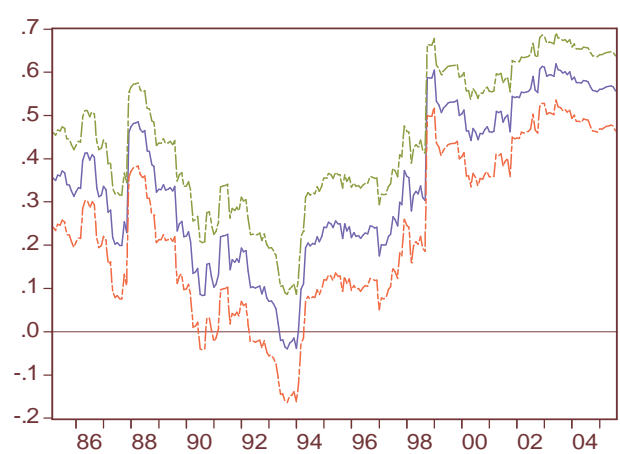

o-Chile-World

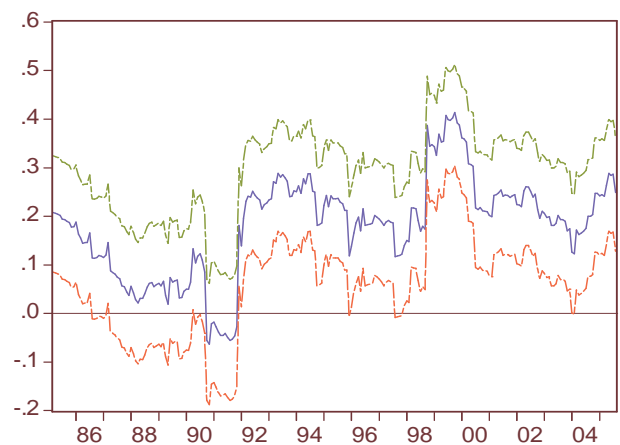

q-Colombia-Venezuela

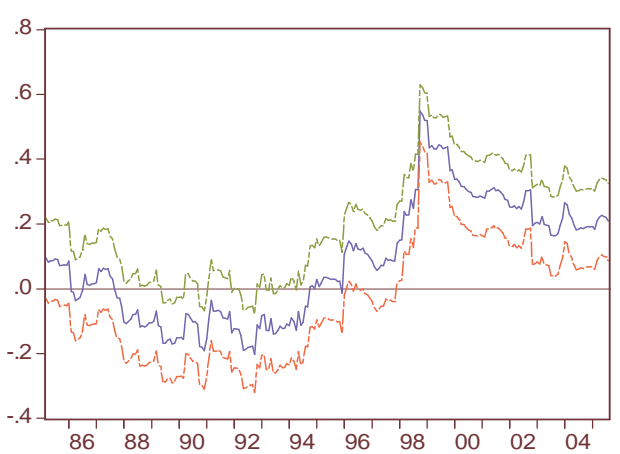

n-Chile-Venezuela

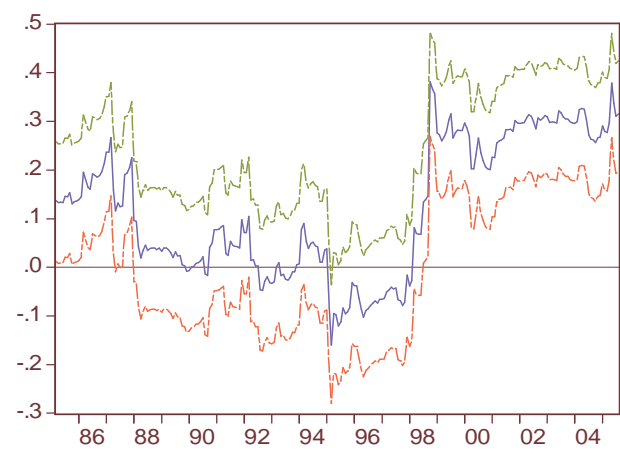

p- Colombia-Mexico

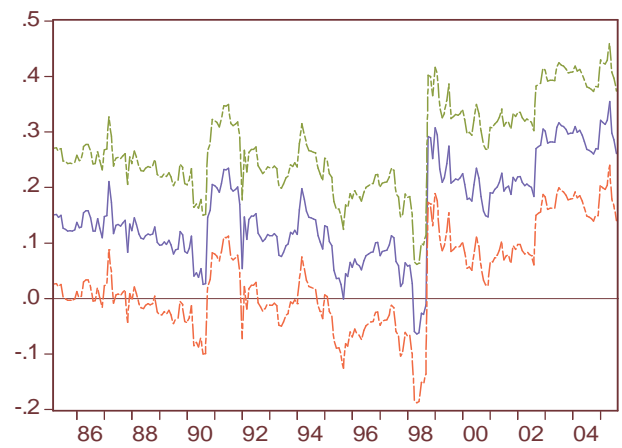

r-Colombia-World 


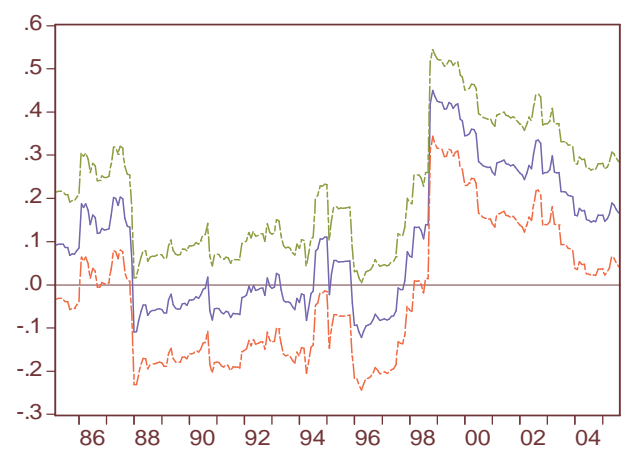

s-Mexico-Venezuela

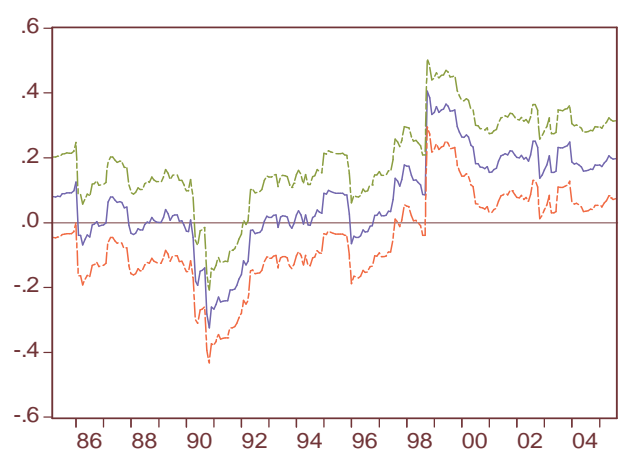

u- Venezuela-World

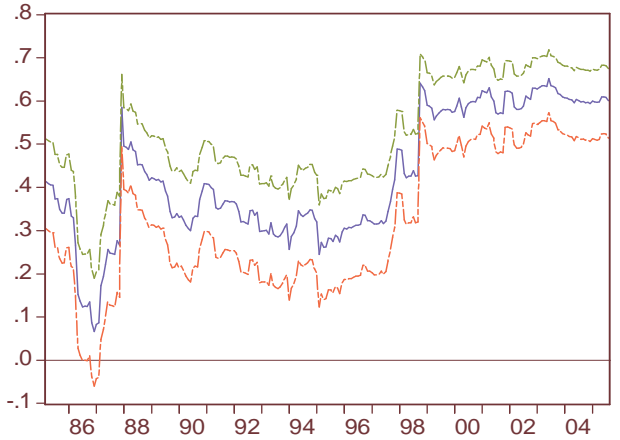

t-Mexico-World 
Figure 2

BIC and residual sum of squares (RSS) for models with $\mathbf{m}$ breakpoints

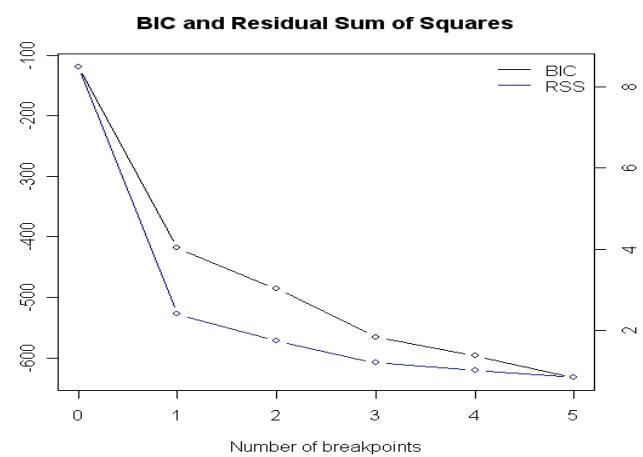

a- Argentina-World

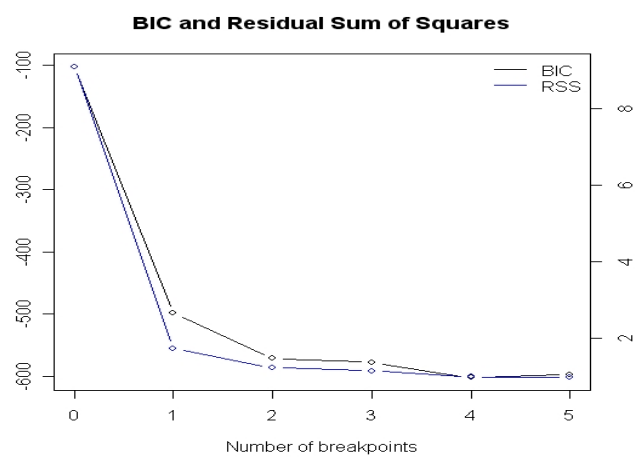

b- Brazil-World

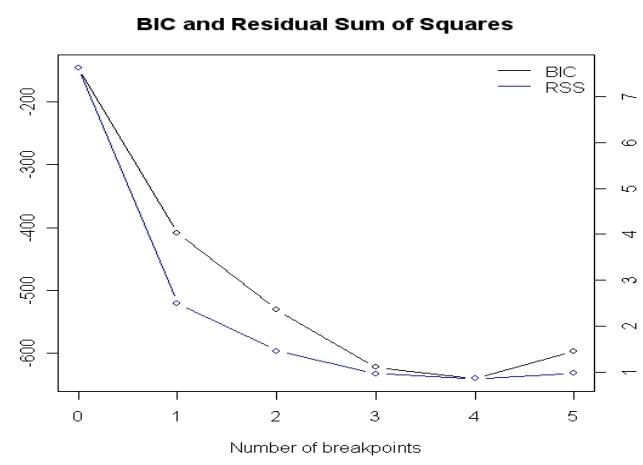

c- Chile-World

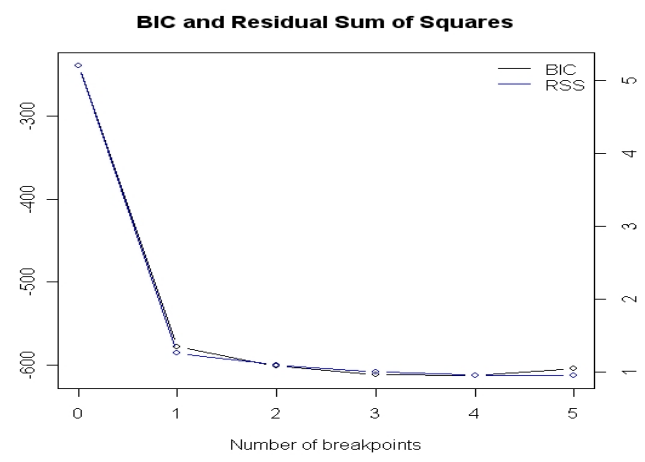

e- Mexico-World

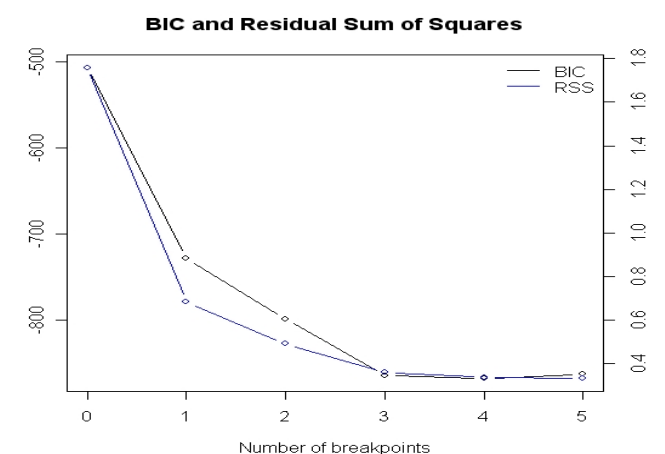

d-Colombia-World

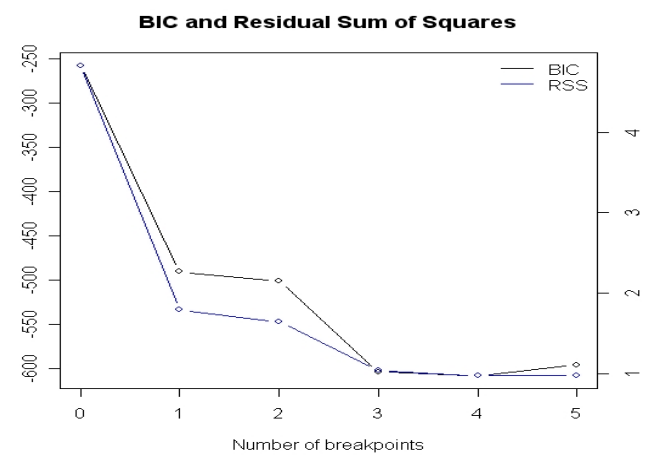

f- Venezuela-World 